\title{
Phenolic content, antioxidant and anti-inflammatory activities of seeds and leaves of date palm (Phoenix dactylifera L.)
}

\author{
Jenny A. John ${ }^{\dagger}$ and Fereidoon Shahidi* \\ Department of Biochemistry, Memorial University of Newfoundland, St.John's, NL, Canada A1B 3X9 \\ †Present Address, Department of Food Science and Technology, Kerala University of Fisheries and Ocean Studies, Kochi, Kerala, India \\ 682506 \\ ${ }^{*}$ Corresponding author: Fereidoon Shahidi, Department of Biochemistry, Memorial University of Newfoundland, St.John's, NL, Canada \\ A1B 3X9. E-mail: fshahidi@mun.ca \\ DOI: $10.31665 / J F B .2019 .5179$ \\ Received: February 4, 2019; Revised received \& accepted: March 22, 2019 \\ Citation: John, J.A., and Shahidi, F. (2019). Phenolic content, antioxidant and anti-inflammatory activities of seeds and leaves of date palm \\ (Phoenix dactylifera L.). J. Food Bioact. 5: 120-130.
}

\begin{abstract}
The total phenolic content of date palm (Phoenix dactylifera L.) seeds (samples 1 and 2) and leaves were determined and for the first time their antioxidant activity in a food system investigated. The anti-inflammatory activity and potency of samples in the inhibition of radical-induced DNA scission and human low-density lipoprotein (LDL) cholesterol oxidation was also evaluated. The total soluble phenolic content of the date palm leaves was 106.96 $\mathrm{mg}$ gallic acid equivalents (GAE)/g sample and ranged from 68.73 to $82.62 \mathrm{mg} \mathrm{GAE} / \mathrm{g}$ of date seeds. Extracts showed good radical scavenging activity in the different in vitro tests conducted in this work and were found to be effective in inhibiting the oxidation of cooked ground meat. Soluble phenolic extract from date seeds of sample 1 was most effective in inhibiting DNA strand scission by $74.15 \%$, while soluble phenolics from palm leaves showed the highest inhibition of LDL cholesterol oxidation (87.82\%). Both samples significantly inhibited mRNA level of COX-2 at concentrations as low as $5 \mu \mathrm{g} / \mathrm{mL}$, with the most potent inhibitory effect being for date palm leaf extracts at $50 \mu \mathrm{g} / \mathrm{mL}$. A number of phenolic compounds including proanthocyanidin dimers, catechin, epicatechin, 5-O-caffeoylshikimic acid isomers, ferulic acid, rutin and isorhamnetin hexoside, among others, were detected in date palm seeds and leaves.
\end{abstract}

Keywords: Date seeds; Leaves; Antioxidant activity; Phenolic profile; DNA breakdown inhibition; LDL oxidation inhibition.

\section{Introduction}

Phoenix dactylifera L. (Date palm) belonging to the family Arecaceae is considered as one of the oldest cultivated fruit trees. It is believed to be indigenous to the countries of the Middle East since at least 6,000 BC (Copley et al., 2001). Saudi Arabia is one of the main homelands of the date palm tree, where it is grown on about $90 \%$ of the cultivated land (Shaheen, 1990). The date palm (Phoenix dactylifera) is dioecious, medium-sized tree with pinnate leaves carrying about 150 leaflets having spines on the petiole. It consists of small yellowish flowers attached directly to the spikelets which develop into fruits. The fruits are known as dates. They are oval-cylindrical in shape and have single seed and their color ranges from bright red to bright yellow when unripe, depending on the variety (Vyawahare et al., 2009).

Date palm fruits serve as an important component of the diet in most of the arid and semiarid regions of the world (Biglari et al., 2008). The various parts of the plant are widely used in traditional medicine for the treatment of a number of disorders, including memory disturbances, fever, inflammation, paralysis, loss of consciousness, and nervous disorders (Anonymous, 1985; Nadkarni, 1976). Many pharmacological studies conducted on date palm fruits have shown that they possess antiulcer (Al-Qarawi et al., 2005), anticancer (Ishurda and John, 2005), anti-diarrhetic (Abdul- 
la and Al-Taher, 2008), hepatoprotective (Mohamed et al., 2008) antimutagenic (Vayalil, 2002), antihyperlipidemic (Salah and AlMaiman, 2005), anti-inflammatory (Mohamed and Al-Okbi, 2004) and antioxidant (Allaith, 2005; Javanmardi et al., 2003) activities, among others. Although the health promoting activities of date palm fruits are well documented, there is hardly any scientific support for the health promoting activities of the bioactives present in their by-products, namely the seeds and the leaves, which have also been used over the centuries for medicinal purposes. This sparked our interest to investigate the bioactive constituents in these by-products and their associated health effects.

The potential antioxidant activity of date palm seeds and leaves was of special interest to us because of the well documented evidence of the role of phenolic compounds as natural scavengers of free radicals and reactive oxygen species (ROS) that cause oxidative damage to lipids, proteins and nucleic acids. Therefore, preventing the formation of free radicals with their deleterious health effects is important in disease risk reduction (Shahidi, 2000). Phenolic compounds have been demonstrated to exhibit positive effects on certain types of cancer (Birt, 2006), coronary heart disease (Hertog et al., 1995), and various inflammatory disorders (Andriantsitohaina et al., 1999). While the exact mechanisms of these effects are unknown, the health promoting activities of compounds involved are often attributed to their phenolic constituents and ability to act as antioxidants, among others. In this study, the total phenolic content of date palm seeds and leaves were evaluated along with their antioxidant potential and phenolic profiles in order to gain insight into their possible application as natural antioxidants with health promoting effects.

\section{Materials and methods}

\subsection{Materials}

Dried, defatted and powdered date seeds (samples 1 and 2) and leaves were kindly provided by Dr. Abdulrahman S. Al-Khalifa, King Saud University, Saudi Arabia. The defatted powdered date seeds were used as such, while the dried palm leaves were ground in a coffee grinder before extraction of the phenolics. The dried samples before extraction and after grinding were made to pass through a $0.5 \mathrm{~mm}$ sieve, vacuum packed and stored in a freezer at $-20{ }^{\circ} \mathrm{C}$ until analyzed. All experiments described below were carried out in triplicates and the results were reported as means \pm standard deviation.

Trolox (6-hydroxy-2,5,7,8-tetramethylchroman-2-carboxylic acid) was purchased from Acros Organics (Fair Lawn, NJ, USA). Organic solvents and reagents such as methanol, acetone and sodium carbonate were purchased from Fisher Scientific Co. (Nepean, ON, Canada). The compounds 2,2'-azobis (2-methylpropionamidine) dihydrochloride (AAPH), 2,2'-azino-bis(3-ethylbenzthiazoline-6-sulphonic acid) (ABTS), Folin and Ciocalteau's phenol reagent, 2,2-diphenyl-1-picrylhydrazyl (DPPH), and all phenolic standards with purity ( $\geq 96 \%$ ) were obtained from Sigma-Aldrich Canada Ltd. (Oakville, ON, Canada). Lipopolysaccharides from Escherichia coli 0111:B4 were acquired from Sigma-Aldrich (St. Louis, MO, USA). TRIzol reagent was purchased from Invitrogen (Carlsbad, CA, USA). StrataScript First Strand complementary DNA Synthesis kit was obtained from Stratagene (Santa Clara, CA, USA). ABI Prism 7900HT Sequence Detection System and TaqMan Universal PCR Master Mix for Real-time PCR were developed by Applied Biosystems (Carlsbad, CA, USA). The TaqMan Assay-On-Demand Gene Expression Assays was pur- chased from Applied Biosystems: COX-2 (Mm01307329_m1), TBP (Mm00446973_m1). All other chemicals were of analytical reagent grade and used without any further purification.

\subsection{Extraction of phenolics}

Soluble and insoluble-bound phenolic compounds were extracted and fractionated as described by Krygier et al. (1982). Powdered date seed and palm leaves $(10 \mathrm{~g})$ were ultrasonicated for $20 \mathrm{~min}$ at $30{ }^{\circ} \mathrm{C}$ with $150 \mathrm{~mL}$ of a mixture of methanol-acetone-water $(7: 7: 6$, $\mathrm{v} / \mathrm{v} / \mathrm{v})$ The resulting slurries were centrifuged at $4,000 \times \mathrm{g}($ ICE Centra MS, International Equipment Co., Needham Heights, MA, USA) for $5 \mathrm{~min}$ and the supernatants collected. The residue was re-extracted under the same conditions, the supernatants combined and desolventized under vacuum at $40{ }^{\circ} \mathrm{C}$ and the resulting slurry which contained soluble phenolics was lyophilized for $72 \mathrm{~h}$ at -48 ${ }^{\circ} \mathrm{C}$ and $46 \times 10^{-3}$ mbar (Freezone 6, model 77530, Labanco Co., Kansas City, MO, USA). The freeze-dried portion represented the soluble phenolics and was stored at $-20^{\circ} \mathrm{C}$ until used for analysis, within a two months period. The bound phenolic acids in the residue obtained after separating the supernatant were isolated according to the procedure described by Krygier et al. (1982). The extracted bound phenolics were dissolved in methanol and stored at $-20{ }^{\circ} \mathrm{C}$ until used.

The palm leaves were dechlorophillized by solvent extraction using dichloromethane as described by Alvarez-Parrilla et al. (2011) before the antioxidant activities of the soluble and bound phenolics were evaluated. The efficiency of the dechlorphyllization procedure was tested by measuring the reduction of absorbance at $660 \mathrm{~nm}$ which is the $\lambda_{\max }$ for chlorophyll and confirmed using HPLC analysis which showed the removal of chlorophyll without affecting the phenolic composition of the extract.

\subsection{Estimation of total phenolic content}

The total phenolic content was determined according to an improved version of the procedure explained by Singleton and Rossi (1965). Folin Ciocalteu's phenol reagent $(0.50 \mathrm{~mL})$ was added to test tubes containing $0.5 \mathrm{~mL}$ of methanolic extracts. Contents were mixed thoroughly and $1 \mathrm{~mL}$ of sodium carbonate $(75 \mathrm{~g} / \mathrm{L})$ was added to each tube. To the mixture, $10 \mathrm{~mL}$ of distilled water were added and vortexed thoroughly. Tubes were then allowed to stand for $45 \mathrm{~min}$ at ambient temperature. Contents were centrifuged for $5 \mathrm{~min}$ at 4,000 $\times \mathrm{g}$ (ICE Centra M5, International Equipment Co., Needham Heights, MA, USA). Absorbance of the supernatant was read at $725 \mathrm{~nm}$. The content of total phenolics in each extract was determined using a standard curve prepared for gallic acid and the results were expressed as $\mathrm{mg}$ of gallic acid equivalents (mg GAE) per gram of sample.

\subsection{In vitro antioxidant assays}

\subsubsection{Total antioxidant capacity by trolox equivalent antioxidant capacity (TEAC)}

The TEAC assay is based on scavenging of 2,2' azinobis-(3-ethylbenzothiazoline-6-sulfonate) radical cation (ABTS $\left.{ }^{+}\right)$and was determined according to the method described by Van den Berg et al. (1999) and modified by John and Shahidi (2010). A solution of $\mathrm{ABTS}^{+}$was prepared in $0.1 \mathrm{M}$ phosphate buffer saline (PBS; 
pH 7.4, 0.15 M sodium chloride) (PBS) by mixing 2.5 mM AAPH with $2.0 \mathrm{mM}$ ABTS stock solution at $1: 1(\mathrm{v} / \mathrm{v})$ ratio. The solution was heated for $12 \mathrm{~min}$ at $60{ }^{\circ} \mathrm{C}$, protected from light and stored at ambient temperature. The radical solution was used within 3 $\mathrm{h}$ as the absorbance of the radical itself depletes with time. Date seed and palm leaf extracts were dissolved in PBS and diluted accordingly to have it fit in the range of values in the standard curve prepared using different concentrations of trolox. To determine TEAC values for date seed and palm leaf extracts, $40 \mu \mathrm{L}$ of samples were mixed with $1.96 \mathrm{~mL}$ of $\mathrm{ABTS}^{+}$solution. The absorbance of the above mixture was read at $734 \mathrm{~nm}$ after 6 min as the extracts needed a minimum of 6 min for completion of the reaction. The decrease in absorption at $734 \mathrm{~nm}$ after 6 min of addition of a test compound was used for calculating TEAC values. Blank measure-

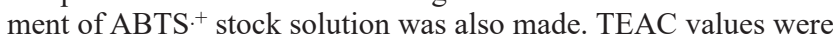
expressed as millimoles of trolox equivalents (TE) per gram of sample. TEAC values were determined as follows:

$$
\begin{gathered}
\Delta A_{\text {Trolox }}=\mathrm{A}_{\text {trolox solution after } 6 \text { min }}-\mathrm{A}_{\text {blank after } 6 \text { min }} \\
\Delta A_{\text {extrac }} t=\mathrm{A}_{\text {extract after } 6 \text { min }}-\mathrm{A}_{\text {blank after } 6 \text { min }} \\
\Delta \mathrm{A}_{\text {Trolox }}=\mathrm{m} \times[\text { Trolox }] \\
\text { TEAC } \mathrm{C}_{\text {extract }}=\left(\Delta \mathrm{A}_{\text {extract }} / \mathrm{m}\right) \times \mathrm{d}
\end{gathered}
$$

where, $\Delta \mathrm{A}=$ reduction of absorbance, $\mathrm{A}=$ absorbance at a given time, $\mathrm{m}=$ slope of the standard curve, $[$ Trolox $]=$ concentration of trolox, $\mathrm{d}=$ dilution factor.

\subsubsection{DPPH radical scavenging capacity (DRSC) using electron paramagentic resonance (EPR)}

DRSC assay was carried out using the method explained by Madhujith and Shahidi (2006). Two millilitres of $0.18 \mathrm{mM}$ solution of DPPH in methanol were added to $500 \mu \mathrm{L}$ of appropriately diluted soluble and bound phenolics extracts in methanol. Contents were mixed well, and after 10 min the mixture was passed through the capillary tubing, which guides the sample through the sample cavity of a Bruker e-scan EPR spectrophotometer (Bruker E-scan, Bruker Biospin Co., Billercia, MA, USA). The spectrum was recorded on a Bruker E-scan food analyzer (Bruker Biospin Co.). The parameters were set as follows: $5.02 \times 10^{-2}$ receiver gain, 1.86 $\mathrm{G}$ modulation amplitude, $2.621 \mathrm{~s}$ sweep time, 8 scans, 100.000 $\mathrm{G}$ sweep width, 3,495.258 $\mathrm{G}$ centre field, $5.12 \mathrm{~ms}$ time constant, $9.795 \mathrm{GH}_{\mathrm{Z}}$ microwave frequency, $86.00 \mathrm{kH}_{\mathrm{Z}}$ modulation frequency, $1.86 \mathrm{G}$ modulation amplitude. For quantitative measurements of radical concentration remaining after reaction with the extracts, the method of comparative determination based on the corresponding signal intensity of first-order derivative of absorption curve was used. DRSC of the extracts was calculated using the following equation:

DPPH radical scavenging capacity $\%=100-($ EPR signal intensity for the medium containing the additive/ EPR signal intensity for the control medium) $\times 100$.

From the standard curve plotted for the DRSC of trolox, the scavenging activity of sample extracts was determined and expressed as $\mathrm{mmol} \mathrm{TE} / \mathrm{g}$ date seed or palm leaf.

\subsubsection{Hydroxyl radical scavenging capacity using EPR}

Hydroxyl radical was generated via Fe (II)-catalyzed Fenton reaction and spin-trapped with DMPO. The resultant DMPOOH adduct was detected using a Bruker E-scan EPR (Bruker Biospin Co., Billercia, MA, USA). Date palm seed and leaf extracts were dissolved in deionized water and appropriately diluted. Trolox was used as a reference antioxidant. Extracts $(100 \mu \mathrm{L})$ were mixed with $100 \mu \mathrm{L}$ of $10 \mathrm{mM} \mathrm{H}_{2} \mathrm{O}_{2}, 200 \mu \mathrm{L}$ of $17.6 \mathrm{mM}$ DMPO, and $100 \mu \mathrm{L}$ of $0.1 \mathrm{mM} \mathrm{FeSO} 4$. After $1 \mathrm{~min}$, the EPR spectrum of the mixture was recorded at $5.02 \times 10^{2}$ receiver gain, $1.86 \mathrm{G}$ modulation amplitude, 2.621 s sweep time, 8 scans, $100.000 \mathrm{G}$ sweep width, 3,495.258 $\mathrm{G}$ centre field, $5.12 \mathrm{~ms}$ time constant, $9.795 \mathrm{GHz}$ microwave frequency, $86.00 \mathrm{kHz}$ modulation frequency, and $1.86 \mathrm{G}$ modulation amplitude. Hydroxyl radical scavenging capacities of the extracts were calculated and expressed as mmol TE/g sample, using the following equation.

Hydroxyl radical scavenging capacity (\%)100 - (EPR signal intensity of extracts/EPR signal intensity of control $) \times 100$.

\subsubsection{Determination of reducing power}

The reducing power of the extracts was determined as described by Amarowicz et al. (2002). A standard curve for trolox was constructed and results were expressed as mmol of TE/g of sample.

\subsubsection{Analysis of oxygen radical absorbance capacity (ORAC)}

The ORAC assay was carried out in accordance with the method detailed by Madhujith and Shahidi (2007) with slight modifications. ORAC $\mathrm{FL}_{\mathrm{FL}}$ was determined using a Fluostar Optima plate reader (BMG Labtech, Durham, NC, USA) equipped with an incubator and two injector pumps with fluorecsein as the probe and AAPH as the radical generator. The reaction was carried out in 75 $\mathrm{mM}$ phosphate buffer ( $\mathrm{pH}$ 7.0) using a 96-well Costar 2650 black plate (Nepean, ON, Canada). To each well, $20 \mu \mathrm{L}$ of phenolic extracts were added followed by $200 \mu \mathrm{L}$ of fluorescein $(0.11 \mu \mathrm{M}$ in PBS). The mixture was incubated for $15 \mathrm{~min}$ at $37^{\circ} \mathrm{C}$ in the builtin incubator of the Fluostar Optima plate reader. The microplate reader was programmed to inject $75 \mu \mathrm{L}$ of AAPH $(17.2 \mathrm{mg} / \mathrm{mL}$ in PBS) into each well, yielding a final well volume of $295 \mu \mathrm{L}$. The plate was shaken for $4 \mathrm{~s}$ after each addition at a $4 \mathrm{~mm}$ shaking width. Fluorescence was determined and recorded every minute for 25 cycles (cycle time, $210 \mathrm{~s}$ ). Results were calculated using the differences in the area under the fluorescein decay curve between the blank and the sample and expressed as mmol TE/g of defatted material. TE was calculated using a standard curve prepared with trolox. A blank was also run using only phosphate buffer and fluorescein. Excitation filter for an excitation wavelength of 485 $\mathrm{nm}$ and emission filter for an emission wavelength of $520 \mathrm{~nm}$ were used.

\subsection{Determination of 2-thiobarbituric acid reactive substances (TBARS) in cooked ground meat system}

Shoulder meat used for this test was purchased from a local supermarket and analyzed for its fat content. The fat content of the ground meat sample was $12.73 \pm 0.27 \%$, as determined according to the Bligh and Dyer (1959) method as modified by Shahidi (2001).

To determine the activity of samples for inhibiting TBARS formation, the method described by Shahidi and Alexander (1998) was followed with slight modifications. To prepare the meat model system, $80 \mathrm{~g}$ of freshly ground meat (5 days postmortem) were 
mixed with $20 \mathrm{~mL}$ of deionized water in a Mason jar. Test samples were added to the meat at a concentration of $200 \mathrm{ppm}$ GAE (gallic acid equivalents), calculated from the values of the total phenolic content assay). A positive control was prepared by adding $200 \mathrm{ppm}$ of butylated hydroxyanisole (BHA) and a control was prepared without any antioxidant. Meat systems were thoroughly mixed and cooked in a water bath at $80^{\circ} \mathrm{C}$ for 30 min with occasional stirring. After cooling to room temperature, the samples were homogenized, transferred into plastic bags and stored at $4{ }^{\circ} \mathrm{C}$ until analyzed for TBARS on days $0,2,5,7,10$, and 14 after preparation. Briefly, 2.0 $\mathrm{g}$ of each meat mixture were blended with $5.0 \mathrm{~mL}$ of $10 \%(\mathrm{w} / \mathrm{v})$ trichloroacetic acid (TCA). Then $5.0 \mathrm{~mL}$ of $0.02 \mathrm{M}$ 2-thiobarbituric acid (TBA) solution were added and the mixture was vortexted for $30 \mathrm{~s}$ and then centrifuged at $1,000 \mathrm{~g}$ for $10 \mathrm{~min}$. The supernatant was filtered through a Whatman no. 3 filter paper and heated in a boiling water bath for $45 \mathrm{~min}$. The solution was cooled to room temperature and the absorbance was subsequently read at $532 \mathrm{~nm}$. A standard curve was prepared using 1,1,3,3-tetramethoxypropane $(1-6 \mu \mathrm{g} / \mathrm{mL})$ as malondialdehyde (MDA) precursor. The TBARS values were then calculated using the standard curve and expressed as milligrams MDA equivalents per $\mathrm{kg}$ sample.

\subsection{Inhibition of peroxyl and hydroxyl radical induced super- coiled DNA strand scission}

The inhibition activity of the date seed and palm leaf extracts against supercoiled DNA strand scission induced by peroxyl and hydroxyl radicals was evaluated according to the method of Chandrasekara and Shahidi (2011) with slight modifications. Supercoiled plasmid DNA (pBR 322 from Escherichia coli RRI) was dissolved at a concentration of $25 \mu \mathrm{g} / \mathrm{mL}$ in $10 \mathrm{mM}$, pH 7.4 phosphate buffer solution (PBS). In an Eppendorf tube, $4 \mu \mathrm{L}$ of supercoiled plasmid DNA solution $(50 \mu \mathrm{g} / \mathrm{mL})$ were added to 2 $\mu \mathrm{L}$ of sample and $4 \mu \mathrm{L}$ of AAPH (22.5 mM in PBS), in the order stated for peroxyl radical-induced oxidation. The mixture was centrifuged and incubated at $37^{\circ} \mathrm{C}$ for $1 \mathrm{~h}$. Upon completion of incubation, the loading dye $(2 \mu \mathrm{L})$, consisting of $0.25 \%$ bromophenol blue, $0.25 \%$ xylene cyanol and $50 \%$ glycerol in distilled water, was added to the reaction mixture. A control with DNA alone and a blank devoid of phenolic extracts were also prepared.

The samples were loaded onto a $0.7 \%(\mathrm{w} / \mathrm{v})$ agarose gel prepared in Tris-acetic acid-EDTA (TAE) buffer (40 mM Tris acetate, $1 \mathrm{mM}$ EDTA, $\mathrm{pH}$ 8.5) containing SYBR safe DNA gel stain (5 $\mu \mathrm{L} / 50 \mathrm{~mL}$ of gel). Gel electrophoresis was run at 85 Volt for 75 min at $4{ }^{\circ} \mathrm{C}$ using a model $\mathrm{B} 1 \mathrm{~A}$ horizontal mini gel electrophoresis system (Owl Separation systems Inc., West Chester, PA, USA) in TAE buffer. The bands were visualized under UV light using Alpha-Imager ${ }^{\mathrm{TM}}$ gel documentation system (Cell Biosciences, Santa Clara, CA, USA). The images were analyzed using Chemilmager 4400 software (Cell Biosciences, Santa Clara, CA, USA) to quantify DNA scission. The protective effect of the date seed and palm leaf extracts was calculated using retention percentage of the supercoiled DNA based on the following equation:

DNA retention, $\%=($ Intensity of supercoiled

DNA with the oxidative radical and extract/intensity of supercoiled DNA in control) $\times 100 \%$.

\subsection{Cupric ion induced human low density lipoprotein (hLDL) peroxidation}

The method of Chandrasekara and Shahidi (2011) was used to measure the human LDL cholesterol oxidation inhibitory activities of date seed and palm leaf extracts. Human LDL cholesterol (in PBS, pH 7.4, with $0.01 \%$ EDTA) was dialyzed against $10 \mathrm{mM}$ PBS $(\mathrm{pH} 7.4,0.15 \mathrm{M} \mathrm{NaCl})$ for $12 \mathrm{~h}$ under nitrogen at $4{ }^{\circ} \mathrm{C}$, and EDTAfree LDL was subsequently diluted to obtain standard option concentration of $0.1 \mathrm{mg} / \mathrm{mL}$ with PBS. The diluted LDL cholesterol solution $(0.8 \mathrm{~mL})$ was mixed with $100 \mu \mathrm{L}$ of extract $(0.125$ and 0.5 $\mathrm{mg} / \mathrm{mL}$ ) in an Eppendorf tube. Oxidation of LDL cholesterol was initiated by adding $0.1 \mathrm{~mL}$ of $100 \mu \mathrm{M} \mathrm{CuSO}_{4}$, solution in distilled water. The mixture was incubated at $37^{\circ} \mathrm{C}$ for $20 \mathrm{~h}$. The initial absorbance $(\mathrm{t}=0)$ was read at $234 \mathrm{~nm}$ immediately after mixing and conjugated diene (CD) hydroperoxides formed at the end of 20 $\mathrm{h}$ were measured. The correct absorbance at $20 \mathrm{~h}$ against $0 \mathrm{~h}$ was employed to calculate the percentage inhibition of $\mathrm{CD}$ formation using the following equation:

$$
\begin{gathered}
\% \text { inhibition of } \mathrm{CD} \text { formation }=\left(\mathrm{Abs}_{\text {oxidative }}-\right. \\
\left.\mathrm{Abs}_{\text {sample }}\right) /\left(\mathrm{Abs}_{\text {oxidative }}-\mathrm{Abs}_{\text {native }}\right) \times 100
\end{gathered}
$$

where $\mathrm{Abs}_{\text {oxidative }}=$ absorbance of LDL mixture and distilled water with $\mathrm{CuSO}_{4}$ only, $\mathrm{Abs}_{\text {sample }}=$ absorbance of LDL with extract and $\mathrm{CuSO}_{4}$, and $\mathrm{Abs}_{\text {native }}=$ absorbance of LDL with distilled water.

\subsection{Inhibition of LPS stimulated COX-2 expression in J774A.1 mouse macrophage cells}

\subsubsection{Cell and cell culture condition}

The J774A1 cells were obtained from American Type Culture Collection (ATCC, Menassas, VA, USA). J774A.1 cells were cultured in DMEM media with $10 \%$ fetal bovine serum and $1 \%$ Amphotericin $\mathrm{B} /$ Streptomycin/Penicillin at $37^{\circ} \mathrm{C}$ and $5 \% \mathrm{CO}_{2}$. All experiments for J774A.1 were conducted in the same medium.

\subsection{2. mRNA isolation, CDNA synthesis and gene expression anal-} ysis

To determine the mRNA expression levels in J774A.1 mouse macrophages, cells were cultured in 6 well plates (Costar, Corning Incorporated, Corning, NY, USA) overnight. J774A.1 cells were incubated in DMEM media with $10 \%$ fetal bovine serum and $1 \%$ antibiotic/antimycotic. Samples $(50,20$ and $5 \mu \mathrm{g} / \mathrm{mL})$ were used to treat the macrophages, and media were replaced every $24 \mathrm{~h}$. After $48 \mathrm{~h}$ incubation, for the control group, media were replaced, and for induction group, $10 \mathrm{ng} / \mathrm{mL}$ LPS were added into the media for inducing pro-inflammatory mediators (Huang et al., 2012). After $4 \mathrm{~h}$ induction, culture medium was discarded and cells were collected according to the previously published protocol (Trasino et al., 2009). Briefly, cells were washed with PBS twice and TRIzol reagent was added for total RNA isolation. StrataScript First Strand complementary DNA Synthesis kit (Stratagene, Santa Clara, CA, USA) was used to reverse transcribed complementary DNA. Inhibitory effect of date seed and palm leaf phenolic extracts on COX-2 expression was examined by real-time PCR. Real-time PCR was performed on ABI Prism 7900HT Sequence Detection System using TaqMan Universal PCR Master Mix. The TaqMan gene expression assay for prostaglandin-endoperoxide synthase 2 (COX-2) was acquired from Applied Biosystems (Carlsbad, CA, USA) and used for gene detection. The mRNA amounts were normalized to an internal control, TATA (thymine adenine thymine adenine)-binding protein (TBP) mRNA. The following amplification parameters 
Table 1. Total phenolic content of date seeds and date palm leaves ${ }^{1}$

\begin{tabular}{|c|c|c|c|}
\hline \multirow{2}{*}{ Sample } & \multirow{2}{*}{$\begin{array}{l}\text { Crude yield of soluble } \\
\text { phenolics (g/100g sample) }\end{array}$} & \multicolumn{2}{|c|}{ Total phenolics (mg GAE/g sample) } \\
\hline & & Soluble phenolics & Bound phenolics \\
\hline Date seed 1 & 15.14 & $68.73 \pm 0.95^{a}$ & $2.43 \pm 0.06^{d}$ \\
\hline Date seed 2 & 13.81 & $82.62 \pm 3.70^{b}$ & $2.50 \pm 0.12^{d}$ \\
\hline Palm leaves & 30.23 & $106.96 \pm 1.76^{c}$ & $0.49 \pm 0.01^{e}$ \\
\hline
\end{tabular}

${ }^{1}$ Data are expressed as means $\pm S D(n=3)$. Means \pm SD followed by the same letter within a column are not significantly different $(p>0.05)$.GAE, gallic acid equivalents.

were used for PCR: $50{ }^{\circ} \mathrm{C}$ for $2 \mathrm{~min}, 95^{\circ} \mathrm{C}$ for $10 \mathrm{~min}$, and $46 \mathrm{cy}$ cles of amplification at $95^{\circ} \mathrm{C}$ for $15 \mathrm{sec}$ and $60{ }^{\circ} \mathrm{C}$ for $1 \mathrm{~min}$.

\subsection{High performance liquid chromatographic (HPLC) analysis of phenolic compounds}

Free and bound phenolic compounds were identified and quantified using high performance liquid chromatography with photodiode array detection (HPLC-DAD) and electrospray ionization mass spectrometry (HPLC-ESI-MS/MS) according to the method of John and Shahidi (2010). Phenolic compounds were analyzed using an Agilent 1100 Series HPLC system (Agilent Technologies, Palo Alto, CA, USA) equipped with a quaternary pump (model G1311A), a degasser (model G1379A), an autosampler (automatic liquid sampler, ASL, model G1329A) and a diode array detector (Model G1315B DAD) linked to an HP-ChemStation data handling system. Twenty five microliters of the sample extracts were automatically injected into a prepacked Supelcosil ${ }^{\mathrm{TM}} \mathrm{LC}-18$ column $(250 \mathrm{~mm} \times 4.6 \mathrm{~mm}$ inner diameter, 5- $\mu \mathrm{m}$ particles, Supelco, Bellefonte, PA, USA) at room temperature. A gradient profile using two solvents was applied at room temperature (Wijeratne et al., 2006), with solvent A: 5\% aqueous formic acid and solvent B: acetonitrile/methanol $(5: 95, \mathrm{v} / \mathrm{v})$ and a flow rate of $0.8 \mathrm{~mL} / \mathrm{min}$. The gradient was as follows: $0 \mathrm{~min}-15 \% \mathrm{~B} ; 7 \mathrm{~min}-31 \% \mathrm{~B}$; $14 \min -47 \% \mathrm{~B} ; 21 \mathrm{~min}-63 \% \mathrm{~B} ; 25 \min -85 \% \mathrm{~B} ; 32 \mathrm{~min}-$ $95 \% \mathrm{~B}$. The wavelengths of the diode array detector (DAD) were set at 280, 325 and $360 \mathrm{~nm}$ for monitoring phenolic compounds. Tentatively identified phenolic compounds were quantified on the basis of their peak areas and comparison with a calibration curve obtained with the corresponding standards.

For HPLC-MS analysis, an Agilent 1100 SL LC/MSD ion trap mass spectrometer (Agilent Technologies, Palo Alto, CA, USA) was connected to the Agilent 1100 HPLC system via an ESI interface in the negative ion detection mode. The MS revealed the negative molecular ions; MS-MS broke down the most abundant one with dependent collision-induced dissociation. The selected values for spray chamber parameters were as follows: capillary potential, 3,500 V; gas temperature, $350{ }^{\circ} \mathrm{C}$; drying gas flow, $13 \mathrm{~L}$ $\mathrm{min}^{-1}$; nebulizer pressure, $414 \mathrm{kPa}$. For full scan MS analysis, the spectra were recorded in the range of $m / z 50-700$. Identification of compounds by HPLC-MS analysis was carried out by comparing retention times and mass spectra of the unknown peaks to those of the standards.

\subsection{Statistical analysis}

Statistical analysis was performed using SigmaStat version 10.0 (Jandel Corp., San Raphael, CA, USA). Results were subjected to ANOVA, and differences between means were located using Tukey's multiple comparison test. Correlations between various parameters were also investigated. Significance was determined at $\mathrm{p} \leq 0.05$ level. All data were reported as the mean \pm SD for three replications.

\section{Results and discussion}

\subsection{Total phenolic content}

The yields of soluble phenolics extract from date seed 1, 2 and palm leaves were $15.14,13.81$ and $30.23 \mathrm{~g} / 100 \mathrm{~g}$ sample, respectively (Table 1). The content of total soluble phenolics in these extracts, expressed as $\mathrm{mg}$ gallic acid equivalents (GAE)/g samples, was in the decreasing order of palm leaves (106.96), date seed 2 (82.62) and date seed 1 (68.73) (Table 1). The total phenolics were predominantly in the soluble rather than the bound form in all three samples tested. Although palm leaves had higher soluble phenolics content, the bound phenolics were 5 times lower than those of the date seeds. There was also a significant $(p \leq 0.05)$ difference between the contents of soluble phenolics of the tested samples, but the difference in the content of bound phenolics between the two date seed samples was insignificant $(\mathrm{p}>0.05)$.

The literature on the phenolic content and antioxidant activities of date seeds and date palm leaves is scarce, though considerable work has been carried out on date fruit. The total phenolics in date fruit varied from 2.49 to $8.36 \mathrm{mg}$ of GAE/g FW (Mansouri et al., 2005; Wu et al. 2004a; 2004b), which is much lower than that in date seeds. The total content of phenolics in date seeds was $1.02-44.30 \mathrm{mg}$ of GAE/g fresh weight (Al-Farsi et al., 2007). This is much lower than that in the present study, probably because dried seeds were used in this study. Al-Turki (2008) also reported that the total phenolics of date seeds ranged from 66.68 (Hilali US) to 14.51 (Amir Hajj US) mg GAE/g dry weight. Messaoudi et al. (2013) studied the total phenolic content of methanol and ethyl-acetate extracts of seeds from seven Algerian palm date (Phoenix dactylifera L.) fruit varieties. The total phenolic content of the methanolic extracts ranged from 27.2 to $38.5 \mathrm{mg}$ of caffeic acid equivalents (CAE)/100g fresh weight, while the content in ethyl acetate extracts ranged from 22.8 to $42.6 \mathrm{mg} \mathrm{CAE} / 100 \mathrm{~g}$ fresh weight. All the varieties tested contained mainly catechin or

epicatechin derivatives, as well as derivatives ofsinaptic acid, cinnamic acid, and coumaric acid. Thus, the by-products of dates, namely the seeds and leaves, had much higher phenolics content than the fruit which can be exploited as a valuable source of bioactive phenolics.

\subsection{Antioxidant activity Assays}

The antioxidant activity of the phenolic compounds in date seeds and palm leaves were assessed using five different antioxidant 
activity assays, namely, TEAC, DPPH and hydroxyl radicals scavenging activities, reducing power and ORAC assay. As different ROS have different reaction mechanisms, it is necessary to use multiple assays to compare foods, dietary supplements, and botanicals for prediction of their antioxidant efficacy (Prior and Cao, 2000; Prior et al., 2003; Phipps et al., 2007). The remarkable antioxidant activities of date seeds and palm leaves in these different systems were analyzed and the results are presented in Table 2. Trolox (6-hydroxy-2,5,7,8-tetramethylchroman-2-carboxylic acid), was used as the calibration standard in all tests, and the results are expressed as mmol trolox equivalents (TE)/g sample. The samples followed a similar trend with respect to their antioxidant capacities, with the soluble phenolics in palm leaves exhibiting a higher activity than date seeds. However, the bound phenolics in palm leaves showed much lower activities than those in date seeds. However, there was no significant $(\mathrm{p}>0.05)$ difference between the antioxidant activities of the two date seed samples. A relationship existed between the content of phenolic compounds and antioxidant activity, showing that samples with higher phenolic content are more effective free radical scavengers.

With respect to antioxidant activity of date seeds and palm leaves, little information is available in the existing literature. AlTurki (2008) reported TEAC values ranging from 0.68 to 0.046 mmole per gram of dry weight in Hilali US and Hayany (US) date seeds, respectively. Meanwhile, the DPPH values ranged from 0.016 to 0.004 mmole TEAC/g of dry weight in Sukari (SA) and Khalasa (SA) seeds, respectively. However, no literature values existed for the other antioxidant activity assays employed here for date seeds, though they have been conducted for date fruits.

Kriaa et al. (2012) examined the antioxidant capacity and phenolic content of three varieties of Phoenix dactylifera leaves, namely Deglet Nour, Medjhoul, and Barhee.All the extracts tested exhibited antioxidant and radical-scavenging activities at different levels and potencies. Correlation analysis indicated that there was a linear relationship between antioxidant potency, free radicalscavenging ability, and the content of phenolics and flavonoids in the exytracts of Phoenix dactylifera leaves.

It is clear that consumption of date fruits at Tamar stage provides a total antioxidant value equivalent to several common fruits such as sweet cherry, orange fruit and Brussels sprouts (Blomhoff, 2005). Thus, compared to these fruits, dates are considered as a good source of antioxidants, mainly due to their phenolics which are the major contributors to antioxidant activity (Allaith, 2008) and potential health benefits (Al-Turkri, 2008).

\subsection{Inhibition of oxidation in meat model system}

Lipid oxidation is a major cause for quality deterioration in muscle foods that lead to the formation of a number of products which are responsible for off odour and off flavour development (Kanner et al., 1991). The TBARS values of antioxidant-treated meat samples stored at $4{ }^{\circ} \mathrm{C}$ over 14 days are shown in Table 3 . The extracts and reference antioxidants (BHA and chlorogenic acid) were added at $200 \mathrm{ppm}$ GAE. The extracts were effective in inhibiting the oxidation of cooked meat in comparison with the control which showed the highest TBARS values at the end of a 14-day storage period. The samples arranged in the order of their effectiveness in inhibiting the formation of TBARS, reflecting their phenolic content, is as follows, BHA $>$ Date seeds $2>$ Dechlorophilized Palm leaves $>$ Palm leaves as such $>$ Date seeds $1>$ Control.

Martín-Sánchez et al (2014) studied the effect of date palm co-products and annatto extract on lipid oxidation and microbial quality in a pork liver pâté. The spreadable pork liver pâtés were 
Table 3. Effect of different antioxidants (soluble extracts at $200 \mathrm{ppm}$ GAE) on the formation of TBARS in a cooked lean meat model system ${ }^{1}$

\begin{tabular}{|c|c|c|c|c|c|c|c|}
\hline \multirow{2}{*}{ Soluble extracts added to pork } & \multirow{2}{*}{$\begin{array}{l}\text { Concentration. } \\
\text { (g/kg pork) }\end{array}$} & \multicolumn{6}{|c|}{ TBARS (mg of MDA equiv/kg pork) } \\
\hline & & Day 0 & Day 2 & Day 5 & Day 7 & Day 10 & Day 14 \\
\hline Control & - & $3.14 \pm 0.14$ & $4.75 \pm 0.18$ & $4.89 \pm 0.12$ & $4.46 \pm 0.10$ & $4.85 \pm 0.27$ & $5.71 \pm 0.11$ \\
\hline $\mathrm{BHA}$ & 0.20 & $1.07 \pm 0.14$ & $0.95 \pm 0.05$ & $0.65 \pm 0.05$ & $0.48 \pm 0.04$ & $0.68 \pm 0.04$ & $0.75 \pm 0.02$ \\
\hline Palm leaves, dechlorophillized & 0.50 & $0.74 \pm 0.01$ & $2.14 \pm 0.02$ & $2.40 \pm 0.09$ & $2.13 \pm 0.03$ & $3.01 \pm 0.03$ & $3.50 \pm 0.11$ \\
\hline Palm leaves, as such & 0.50 & $1.20 \pm 0.10$ & $2.58 \pm 0.13$ & $2.59 \pm 0.06$ & $2.88 \pm 0.06$ & $3.67 \pm 0.15$ & $4.15 \pm 0.22$ \\
\hline Date seeds 1 & 0.46 & $0.86 \pm 0.09$ & $3.13 \pm 0.02$ & $3.79 \pm 0.17$ & $3.78 \pm 0.09$ & $3.37 \pm 0.05$ & $4.63 \pm 0.10$ \\
\hline Date seeds 2 & 0.30 & $1.05 \pm 0.49$ & $1.78 \pm 0.09$ & $2.64 \pm 0.07$ & $2.68 \pm 0.05$ & $3.52 \pm 0.17$ & $3.35 \pm 0.16$ \\
\hline
\end{tabular}

${ }^{1}$ Data are expressed as means \pm SD $(n=3)$. Abbreviations: MDA, malondialdehyde; and BHA, butylated hydroxyanisole.

made using fresh date coproducts $(2.5$ and $7.5 \%)$ as a potential functional ingredient and an ethanolic annatto extract $(128 \mathrm{mg} / \mathrm{kg})$ as colorant. The effect of these 2 ingredients on lipid oxidation and microbial quality of the pâtés was assessed during a 21 day storage. The pâtés containing $7.5 \%$ date paste had the highest content of phenolic compounds during storage. The combination of $2.5 \%$ date paste and annatto protected pâtés against lipid oxidation throughout the entire storage period.

\subsection{Supercoiled plasmid DNA strand scission inhibition}

DNA molecules are easily attacked by free radicals that induce base modification and strand scission; this leads to mutagenesis and possibly cancer. Thus, the effectiveness of the extracts to prevent the DNA strand scission is a reflection of their positive effects against many diseases. Peroxyl radicals used in the present study are known to exert oxidative damage in biological systems due to their comparatively long half-life and thus greater affinity to diffuse into biological fluids in cells (Hu and Kitts, 2001). Soluble extracts from the dates and palm leaf samples were dissolved in PBS at a concentration of $0.3 \mathrm{mg} / \mathrm{mL}$ before mixing them with DNA. Figure 1 shows the percentage of supercoiled DNA strands retained after incubation with peroxyl radicals generated by AAPH. Soluble phenolic extract from date seeds 1 was most effective showing a DNA strand scission inhibition of $74.15 \%$, followed closely by dates seeds 2 (72.83\%); while bound phenolic extract from leaves was least effective with 3.14\% inhibition.

Radicals cleave supercoiled pBR 322 plasmid DNA (form I) to nicked circular DNA (form II) as shown in Figure 2. Lane 1 represents the native DNA without any additives and lane 2 represents the blank, where the reaction mixture does not contain any antioxidant. The presence of a high intensity form II band and the disappearance of form I band in lane 2 indicate that the DNA was completely nicked. The date seed and palm leaf extracts which were added in the remaining wells showed good strand scission inhibiting activity as is clearly displayed by the greater intensity of form I band or the supercoiled plasmid DNA.

The DNA scission inhibitory effects of the date and palm leaf extracts, as observed in the present study, may be due to their ability to scavenge peroxyl radicals as shown in ORAC and TEAC assays (Table 2).

\subsection{Inhibition of cupric ion-induced human LDL cholesterol per- oxidation}

Oxidation of polyunsaturated lipid components of LDL cholesterol by ROS plays a key role in the pathogenesis of atherosclerosis (Esterbauer, 1993). Furthermore, transition metal ions may promote oxidative modification of LDL cholesterol through hydroperoxides (Decker et al., 2001). According to Decker et al. (2001), both free radical scavenging and copper chelating activity of antioxidants are responsible for inhibition of LDL cholesterol oxidation.

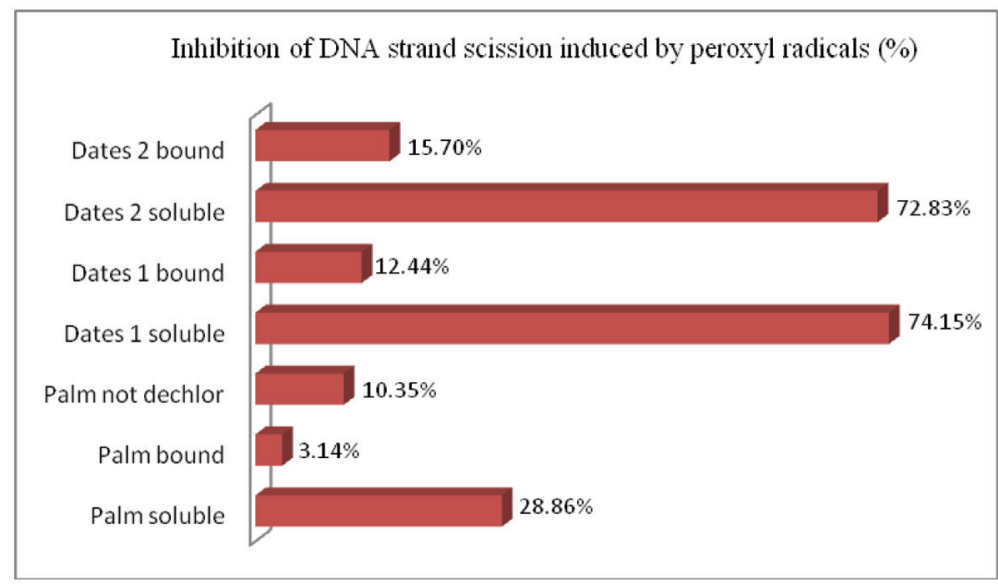

Figure 1. Inhibition percentage of supercoiled pBR 322 plasmid DNA scission in peroxyl radical-mediated systems with extracts from date seeds and palm leaf. 


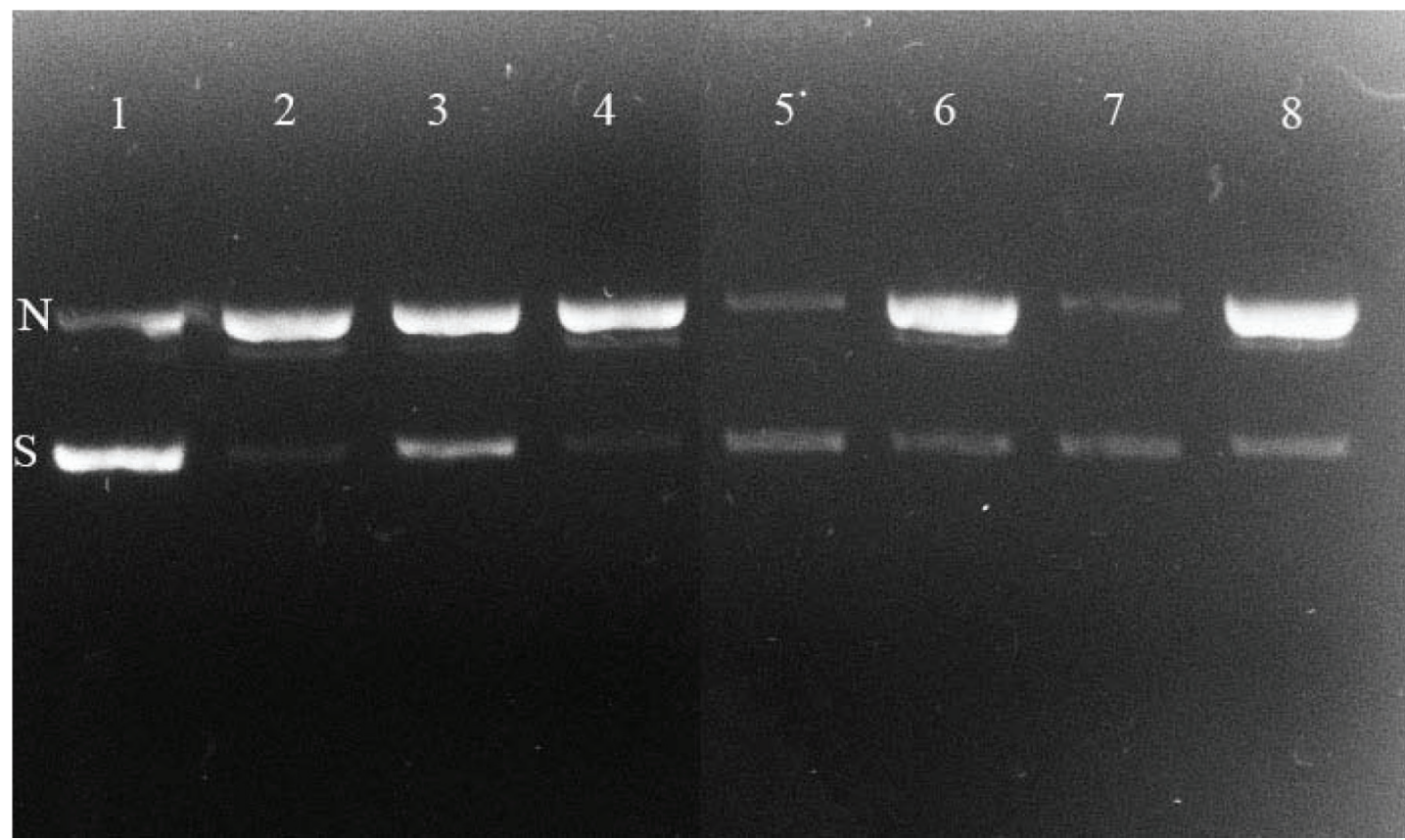

Figure 2. Effect of addition of palm leaf and date seed phenolic extracts in peroxyl radical treated DNA system Lane 1: Control (DNA only); Lane 2: Blank (DNA and AAPH); Lane 3: soluble palm leaf extract ; Lane 4: bound palm leaf extract; Lane 5: Soluble date seeds 1 extract; Lane 6: Bound date seeds 1 extract; Lane 7: Soluble date seeds 2 extract; Lane 8: Bound date seeds 2 extract; S, supercoiled plasmid DNA strands; N, nicked DNA strands.

The antioxidant activity of date seed and palm leaf soluble phenolic extracts was determined by measuring the concentration of conjugated dienes formed during copper-catalyzed human LDL cholesterol oxidation in vitro, and the results were expressed as percentage inhibition of oxidation based on the CD value after $20 \mathrm{~h}$ incubation (Table 4). The soluble phenolics of palm leaves showed the highest inhibition of $87.82 \%$, followed by soluble extract of date seed $2(74.22 \%)$, and subsequently the soluble phenolics of date seed $1(58.84 \%)$. The mechanism by which phenolics in date seed and palm leaf extracts inhibit LDL cholesterol oxidation may be a combined effect of chelation of cupric ions (which catalyzes the oxidation) as well as scavenging of peroxyl radicals formed (Decker et al., 2001)

\subsection{Inhibition of LPS stimulated COX-2 expression in J774A.1 mouse macrophage cells}

The mRNA expression of the inflammatory mediator, cyclooxygenase-2 (COX-2) was monitored in order to test the involvement of transcriptional events during their biosynthesis. Date seed 2 and palm leaf extracts were tested for their inhibitory effect on lipoploysaccharide (LPS)-stimulated expression of COX-2 in mouse

Table 4. Inhibition of LDL cholesterol oxidation in the presence of date palm leaves and date seed soluble phenolic extracts ${ }^{1}$

\begin{tabular}{ll}
\hline Sample soluble phenolic extract & Inhibition (\%) \\
\hline Palm leaves & $87.82 \pm 3.50^{\mathrm{a}}$ \\
Date seed 1 & $58.84 \pm 1.11^{\mathrm{b}}$ \\
Date seed 2 & $74.22 \pm 5.02^{\mathrm{c}}$ \\
\hline
\end{tabular}

${ }^{1}$ Data are expressed as the mean $\pm S D(n=3)$. Values with different letters in the same column are significantly different $(p<0.05)$. macrophage J774A.1 cells. Date seed 1 extracts were not included in this test due to their lower activity in previous antioxidant tests performed here. Before the anti-inflammatory assay, cytotoxicity of samples was examined; $50 \mu \mathrm{g} / \mathrm{mL}$ of date seed 2 and palm leaf extracts showed inhibitory effect on macrophage growth, while lower concentrations (20 and $5 \mu \mathrm{g} / \mathrm{mL}$ ) did not show any growth inhibitory effect. Samples $(50,20$ and $5 \mu \mathrm{g} / \mathrm{mL})$ were used to treat the macrophages for $48 \mathrm{~h}$ prior to LPS induction. The cells were then incubated with $10 \mathrm{ng} / \mathrm{mL}$ LPS for $4 \mathrm{~h}$ to induce inflammatory effect. Inhibitory effect of samples on COX-2 expression was examined using real-time PCR.

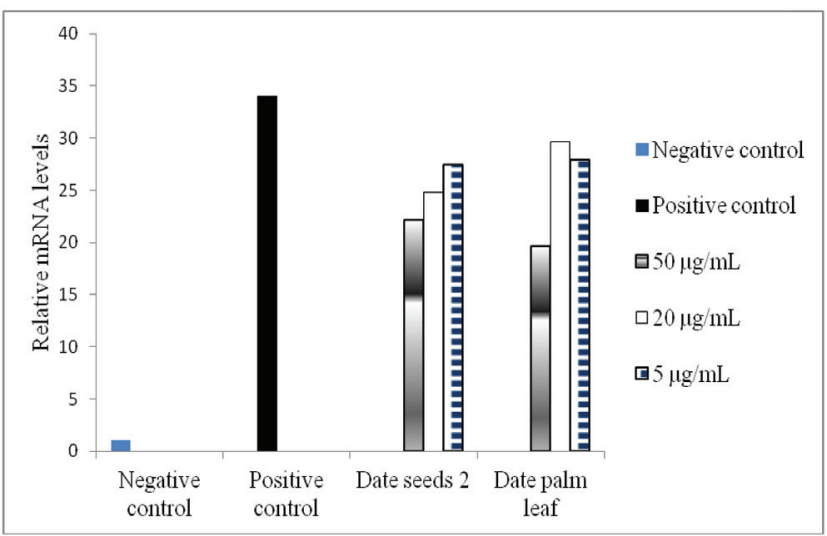

Figure 3. Inhibitory effect of date seed and palm leaf extracts on LPS stimulated COX-2 expression in J774A.1 mouse macrophage cells. Cells were pretreated with samples for $48 \mathrm{~h}$ prior to LPS induction, after $4 \mathrm{~h}$ of induction, RNA was isolated and COX-2 expression was examined. Negative control indicate COX-2 expression level without LPS stimulation and positive control was measured after $10 \mathrm{ng} / \mathrm{mL}$ LPS stimulation for $4 \mathrm{~h}$. 
Table 5. Major phenolic compounds in date palm seeds and leaves identified using HPLC/ESI-MS/MS

\begin{tabular}{|c|c|c|c|c|c|}
\hline No. & Phenolic compound & Retention time (min) & {$[\mathrm{M}-\mathrm{H}]^{-}$} & Fragments & Extracts in which detected ${ }^{1}$ \\
\hline 1 & Caffeoyl hexoside & 4.0 & 342 & 179 & Date seed ${ }^{S}$ \\
\hline 2 & Methyl gallate & 4.1 & 183 & 169 & Date palm leafs \\
\hline 3 & Protocatechuic acid & 7.1 & 153 & 109 & Date palm leaf ${ }^{B}$ \\
\hline 4 & Catechin & 8.4 & 289 & 245,125 & Date seed ${ }^{B}$ \\
\hline 5 & p-Hydroxybenzoic acid & 9.6 & 137 & 93 & Date palm leaf ${ }^{B}$ \\
\hline 6 & Proanthocyanidin dimer isomers & $8.7,9.1,11.4$ & 577 & $425,405,289$ & Date palm leaf ${ }^{S}$, date seed ${ }^{S}$ \\
\hline 7 & Epicatechin & 11.9 & 289 & 245,125 & Date palm leaf ${ }^{S}$, date seed ${ }^{S}$ \\
\hline 8 & 5-O-caffeoylshikimic acid isomers & $12.1,13.0$ & 335 & - & Date seed ${ }^{S}$ \\
\hline 9 & $p$-Coumaric acid & 14.4 & 163 & 119 & Date seed ${ }^{B}$, Date palm leaf ${ }^{B}$ \\
\hline 10 & Apigenin di-C-hexoside & 13.2 & 593 & 325,427 & Date palm leaf ${ }^{S}$ \\
\hline 11 & Ferulic acid & 15.3 & 193 & 178,150 & Date palm leaf ${ }^{B}$ \\
\hline 12 & Quercetin-3-heteroside & 18.0 & 463 & 301 & Date palm leaf ${ }^{\varsigma}$ \\
\hline 13 & Rutin & 18.6 & 609 & 301 & Date palm leaf ${ }^{S, B}$ \\
\hline 14 & Isorhamnetin hexoside & 20.9 & 477 & 462,315 & Date palm leaf $\mathrm{S,B}$ \\
\hline 15 & Isorhamnetin-3-rhamnoglucoside & 21.2 & 623 & 315,300 & Date palm leaf ${ }^{S}$ \\
\hline 16 & Hydrocaffeic acid & 27.2 & 181 & - & Date seed ${ }^{S}$ \\
\hline 17 & Isorhamnetin & 31.5 & 315 & $271,254,151$ & Date seed ${ }^{\mathrm{S}, \mathrm{B}}$ \\
\hline
\end{tabular}

${ }^{1} \mathrm{~S}$, soluble phenolic extracts and $\mathrm{B}$, bound phenolic extract.

In Figure 3, negative control indicate COX-2 expression level without LPS stimulation and positive control was measured after 10 $\mathrm{ng} / \mathrm{mL}$ LPS stimulation for $4 \mathrm{~h}$. It is clear that macrophages treated with LPS alone had the highest levels of COX-2 mRNA, which were lowered by the addition of date seed or palm leaf extracts. Both samples significantly inhibited mRNA level of COX-2 at concentrations as low as $5 \mu \mathrm{g} / \mathrm{mL}$ (Figure 3 ) and a concentration dependent inhibitory effect was observed, with the most potent inhibitory effect being for date palm leaf extracts at $50 \mu \mathrm{g} / \mathrm{mL}$. The level of COX-2 mRNA was reduced by 35.3 and $42.4 \%$ in date seed 2 and palm leaf extract $(50 \mu \mathrm{g} / \mathrm{mL})$ treated macrophages, respectively.

Cyclooxygenase-2 (COX-2)-catalysed synthesis of prostaglandin E2 plays a key role in inflammation and its associated diseases such as cancer and cardiovascular disease (Zhong et al., 2012; Shahidi and Zhong, 2009; O'Leary et al., 2004). There are numerous reports demonstrating that flavonoids inhibit COX-2 activity (Liang et al., 2001; Raso et al., 2001). However, transcriptional regulation of COX-2 can also be important. The effect of date seed and palm leaf extracts on COX-2 mRNA expression suggests the involvement of a pretranslational or transcriptional mechanism in the inhibition of COX-2 protein production. The polyphenols in the extracts may be the main inhibitors of COX-2 activity. Compared to steroidal and non-steroidal chemical drugs for treating inflammation, naturally derived substances are readily available at lower costs with limited side effects and intolerance (Zhong et al., 2012) and it is clear from the above data that date seeds or palm leaves can serve as a natural source of anti-inflammatory substances.

\subsection{High performance liquid chromatographic (HPLC) analysis of phenolic compounds}

The phenolic compounds in date palm seed and leaf extracts were identified on the basis of their retention times, absorbance spectra, and ESI-MS fragmentation pattern which were compared to previously published data (Table 5) (Al-Farsi et al., 2005; Mansouri et al., 2005; Ziouti et al., 1996).

Proanthocyanidin dimer and epicatechin were the common phenolic compounds present in both the date seed and palm leaf soluble phenolic extracts. In HPLC-ESI-MS, the mass spectrum of compound 6 at $\mathrm{m} / \mathrm{z} 577$ gave fragment ions at $\mathrm{m} / \mathrm{z} 425,405$ and 289. In addition, the UV spectrum of compound 6 is similar to that of $(+)$ catechin/(-)epicatechin. Therefore, compound 6 was identified to be a proanthocyanidin dimer. Proanthocyanidin dimer isomers with retention times of 8.7,9.1 and 11.4 min were detected at $m / z 577$ and showed similar fragmentation patterns.

Methyl gallate, apigenin di-C-hexoside, quercetin-3-heteroside, rutin, isorhamnetin hexoside and isorhamnetin-3-rhamnoglucoside were detected only in the soluble phenolic extracts of date palm leaf; while caffeoyl hexoside, 5-O-caffeoylshikimic acid isomers, hydrocaffeic acid and isorhamnetin were present only in the soluble phenolic extracts of date seeds. Alkali hydrolysis of the bound phenolics released certain simple phenolic acids that were not detected in the soluble extracts, Protocatechuic acid, $p$-hydroxybenzoic acid, $p$-coumaric acid, ferulic acid, rutin and isorhamnetin hexoside were present in the bound form in date palm leaf; while catechin, $p$-coumaric acid and isorhamnetin as bound phenolics in the date seed.

Khallouki et al. (2018) determined the phytochemical composition of mature Moroccan Medjool dates (Phoenix dactylifera). The amount of total phenolic compounds, determined by analytical high performance liquid chromatography (HPLC) in combined $2 \%$ aqueous acetic acid and methanol extracts was $61.3 \mathrm{mg} / 100 \mathrm{~g}$ wet weight. The major components were chelidonic acid at $29.44 \mathrm{mg} /$ $\mathrm{kg}$ and di-caffeoyl shikimic acid isomers at $9.49 \mathrm{mg} / \mathrm{kg}$ wet weight, respectively. 
. There is very scanty information in literature with respect to the phenolic profile of date palm seeds and leaves. Ziouti et al. (1996) investigated the phenolic compounds in the leaves and detected catechin, epicatechin, rutin, quercetin-3-galactoside, isorhamnetin-3-rhamnoglucoside, isorhamnetin heteroside and isorhamnetin-3-galactoside. All these compounds were also found in the present study along with others, as listed in Table 5. Flavonoids were found to be the main phenolic compounds in the leaves. They were chiefly flavonol heterosides. These two aglycons (quercetin and isorhamnetin) were previously detected by acid hydrolysis in the leaves of some date palm cultivars (Ouafi et al., 1988). Flavan-3-ols were also part of the phenolic composition of the leaves, the main ones being $(+)$-catechin and (-)-epicatechin. More complex forms of flavans (proanthocyanidins), as detected in the present study, were also reported by Ouafi et al. (1988). Phenolic profiles of date seeds have not previously been reported though there are several reports on the HPLC phenolic profile of date fruits (Al-Farsi et al., 2005; Mansouri et al., 2005; Hong et al., 2006). Caffeoylshikimic acids, which have been characterized in date fruits (Maier and Metzler, 1965), were also detected in date seeds. These are of interest for their potential fungitoxic activity. Caffeic acid derivatives are known to be toxic to microorganisms and could be involved in plant defense mechanisms (Ziouti et al., 1996). Gas chromatography coupled with mass spectrometry (GCMS) analysis of date palm (Phoenix dactylifera L.) revealed that $p$-hydroxybenzoic acid was the major phenolic compound of cell wall-bound phenolics (Boucenna-Mouzali et al., 2018)

The results presented here suggest that date by-products, in particular seeds and leaves, serve as a good source of phenolics with antioxidant activity that could potentially be considered as inexpensive sources of natural antioxidants that could be used in food and non-food applications.

\section{Acknowledgments}

We are grateful to the Natural Sciences and Engineering Research Council (NSERC) of Canada for partial support of this project. We are grateful to Dr. A,S. Al-Khalifa for providing the samples used in this study as well as to Mr. Haiqiu (Jason) Huang and Dr. Liangli (Lucy) Yu for the anti-inflammatory experiments.

\section{References}

Al-Taher, A.Y. (2008). Possible anti-diarrhoeal effect of the date palm (Phoenix Dactylifera L) spathe aqueous extract in rats. Sci. J. King Faisal Univ. (Basic and Applied Sciences) 9: 1429-1435.

Alasalvar, C., Karamać, M., Amarowicz, R., and Shahidi, F. (2006). Antioxidant and antiradical activities in extracts of hazelnut kernel (Corylus avellana L.) and Hazelnut green leafy cover. J. Agric. Food Chem. 54: 4826-4832.

Al-Farsi, M., Alasalvar, C., Morris, A., Baron, M., and Shahidi, F. (2005). Comparison of antioxidant activity, anthocyanins, carotenoids, and phenolics of three native fresh and sun-dried date (Phoenix dactylifera L.) varieties grown in Oman. J. Agric. Food Chem. 53: 7592-7599.

Al-Farsi, M., Alasalvar, C., Al-Abid, M., Al-Shoaily, K., Al-Amry, M., and AlRawahy, F. (2007). Compositional and functional characteristics of dates, syrups, and their byproducts. Food Chem. 104: 943-947.

Allaith, A.A.A. (2005). In vitro evaluation of antioxidant activity of different extracts of Phoenix dactylifera $L$. fruits as functional foods. Deut. Lebensm. Runds. 101: 305-308.

Allaith, A.A.A. (2008). Antioxidant activity of Bahraini date palm (Phoenix dactylifera L.) fruit of various cultivars. Int. J. Food Sci. Technol. 43 1033-1040.
Al-Qarawi, A., Abdel-Rahman, H., Ali, B.H., Mousa, H.M., and El-Mougy, S.A. (2005). The ameliorative effect of dates (Phoenix dactylifera L.) on ethanol-induced gastric ulcer in rats. J. Ethnopharmacol 98: 313-317.

Al-Turkri, S.M. Antioxidant properties of date palm (Phoenix dactylifera L.) Cultivars. Ph.D. Thesis, Department of Horticulture and Landscape Architecture, Colorado State University.

Alvarez-Parrilla, E., de la Rosa, L.A., Amarowicz, R., and Shahidi, F. (2011). Antioxidant activity of fresh and processed Jalapeno and Serrano peppers. J. Agric. Food Chem. 59: 163-173.

Amarowicz, R., Karamać, M., Weidner, S., Abe, S., and Shahidi, F. (2002). Antioxidant activity of wheat caryopses and embryos extracts. J Food Lipids 9: 201-210.

Andriantsitohaina, R., Andriambeloson, E., and Stoclet, J.C. (1999). Pharmacological approaches of endothelial nitric oxide-dependent vasorelaxation induced by polyphenols from plant extracts. Methods Enzymol 301: 522-532.

Anonymous. (1985). The wealth of India (A dictionary of Indian raw materials and industrial products) Raw materials, 1st ed. Council of Scientific and Industrial Research, New Delhi, Vol. 3.

Biglari, F., Abbas, F.M., and Al-Karkhi and Azhar, M.E. (2008). Antioxidant activity and phenolic content of various date palm (Phoenix dactylifera) fruits from Iran. Food Chem 107: 1636-1641.

Birt, D. (2006). Phytochemicals and cancer prevention: from epidemiology to mechanism of action. J Am Diet Assoc 106: 20-21.

Bligh, E.G., and Dyer, W.J. (1959). A rapid method of total lipid extraction and purification. Can J Biochem Phys 37: 911-917.

Blomhoff, R. (2005). Dietary antioxidants and cardiovascular disease. Curr Opin Lipidol 16: 47-54.

Boucenna-mouzali, B., Gaceb-terrak, R., and Rahmania, F. (2018). GC-MS Analysis of Cell Wall-Bound Phenolic Compounds and Lignin Quantification in Date Palm Cultivars that are Resistant or Susceptible to Fusarium oxysporum f. sp. albedinis. Arab J. Sci. Eng. 43(1): 63-71.

Chandrasekara, A., and Shahidi, F. (2011). Bioactivities and antiradical properties of millet grains and hulls. J Agric Food Chem 59: 95639571

Copley, M.S., Rose, P.J., Clampham, A., Edwards, D.N., Horton, M.C., and Evershed, R.P. (2001). Detection of palm fruit lipids in archaeological pottery from Qasr Ibrim, Egyptian Nubia. Proc R Soc Lond 268: 593-597.

Decker, E.A., Ivanov, V., Zhu, B.Z., and Frei, B. (2001). Inhibition of lowdensity lipoprotein-oxidation by carnosine and histidine. J. Agric Food Chem 49: 511-516.

El-Arem, A., Saafi, E.B., Mechri, B., Lahouar, L., Issaoui, M., Hammami, M., and Achour, L. (2012). Effects of the ripening stage on phenolic profile, phytochemical composition and antioxidant activity of date palm fruit. J. Agric. Food Chem 60: 10896-10902.

Esterbauer, H. (1993). Cytotoxicity and genotoxicity of lipid oxidation products. American Am J Clin Nutr 57: 779-786.

Hertog, M.G.L., Kromhout, D., Aravinis, C., Blackburn, H., Fidanza, F., Giampaoli, S., Jansen, A., Menotti, A., and Nedeljkovic, S. (1995). Flavonoid intake and long-term risk of coronary heart disease and cancer in Seven Countries Study. Arch. Intern. Med. 155: 381-386.

Hong, Y.J., Tomas-Barberan, F.A., Kader, A.A., and Mitchell, A.E. (2006). The flavonoid glycosides and procyanidin composition of Deglet Noor dates (Phoenix dactylifera). J. Agric. Food Chem 54: 2405-2411.

Hu, C., and Kitts, D.D. (2001). Evaluation of antioxidant activity of epigallocatechin gallate in biphasic model systems in vitro. Mol Cell Biochem 218: 147-155.

Huang, H., Fletcher, A., Niu, Y., Wang, T.T.Y., and Yu, L. (2012). Characterization of lipopolysaccharide-stimulated cytokine expression in macrophages and monocytes. Inflamm Res 61: 1329-1338.

Ishurda, O., and John, F.K. The anti-cancer activity of polysaccharide prepared from Libyan dates (Phoenix dactylifera L.). Carbohydr Polym 59: 531-535.

Javanmardi, J., Stushno, C., Locke, E., and Vivanco, J.M. (2003). Antioxidant activity and total phenolic content of Iranian Ocimumaccessions. Food Chem. 83: 547-550

John, J.A., and Shahidi, F. (2010). Phenolic compounds and antioxidant activity of Brazil nut (Bertholletia excelsa). J Funct Foods 2: 196-209.

Khalloukia, F., Ricartea, I., Breuera, A., and Owena, R.W. (2018). Charac 
terization of phenolic compounds in mature Moroccan Medjool date palm fruits (Phoenix dactylifera) by HPLC-DAD-ESI-MS. J. Food Compos. Anal. 70: 63-71.

Kriaa, W., Fetoui, H., Makni, M., Zeghal, N., and Drira, N.-E. (2012). Phenolic Contents and Antioxidant Activities of Date Palm (Phoenix dactylifera L.) Leaves. Int J Food Prop. 15(6): 1220-1232.

Krygier, K., Sosulski, F., and Hodge, L. (1982). Free, esterified, and insoluble bound phenolic acids. 1. Extraction and purification procedure. J. Agric. Food Chem 30: 30-334.

Liang, Y.C., Tsai, S.H., Tsai, D.C., Lin-Shiau, S.Y., and Lin, J.K. (2001). Suppression of inducible cyclooxygenase and nitric oxide synthase through activation of peroxisome proliferator-activated receptor-gamma by flavonoids in mouse macrophages. FEBS Letters 496: 12-18.

Madhujith, T., and Shahidi, F. (2007). Antioxidative and antiproliferative properties of selected barley (Hordeum vulgarae L.) cultivars and their potential for inhibition of low density lipoprotein (LDL) cholesterol oxidation. J. Agric. Food Chem 55: 5018-5024.

Martín-Sánchez, A.M., Ciro-Gómez, G.L., Zapata-Montoya, J.E., Vilella-Esplá, J., Pérez-Álvarez, JA, and Sayas-Barberá, E. (2014). Effect of Date Palm Coproducts and Annatto Extract on Lipid Oxidation and Microbial Quality in a Pork Liver Pâté. Food Microbiol.\& Safety 79(11): M2301-M2307.

Maier, V.P., and Metzler, D.M. (1965). Changes in individual date polyphenols and their relation to browning. J Food Sci 30: 747-752.

Mansouri, A., Embarek, G., Kokkalou, E., and Kefalas, P. (2005). Phenolic profile and antioxidant activity of the Algerian ripe date palm fruit (Phoenix dactylifera). Food Chem 89: 411-420.

Messaoudi, R., Abbeddou, S., Mansouri, A., Calokerinos, A.C., and Kefalas, P. (2013). Phenolic profile and antioxidant activity of date-pits of seven Algerian date palm fruit varieties. Int. J. Food Prop. 16(5): 1037-1047.

Mohamed, B.A., Nabil, A.H., and Hanan, A.S. (2008). Protective effects of extract from dates (Phoenix dactylifera L.) and ascorbic acid on thioacetamide-induced hepatotoxicity in rats. Iran J. Pharm. Res. 7: 193-201.

Mohamed, D.A., and Al-Okbi, S.Y. (2004). In vivo evaluation of antioxidant and anti-inflammatory activity of different extracts of date fruits in adjuvant arthritis. Pol. J Food Nutr. Sci. 13: 397-402.

Nadkarni, K.M. (Ed.). (1976). Indian Materia Medica Vol 1. In: Bombay Popular Prakashan Pvt. Ltd., Mumbai.

O'Leary, K., Pascual-Tereasa, S., Needs, P.W., Bao, Y., O’Brien, N.M., and Williamson, G. (2004). Effects of flavonoids and vitamin E on cyclooxygenase (COX-2) transcription. Mutat Res 551: 245-254.

Ouafi, S., Gaceb-Terrak, R., Bounaga, N., and Lebreton, P. (1988). Les flavonoides marqueurs intraspecifiques chez le palmier dattier (Phoenix dactylifera L.). Comptes rendus de l'Académie des Sciences, Paris, Sér. III 306: 399-404.

Phipps, S.M., Sharaf, M.H.M., and Butterweck, V. (2007). Assessing Antioxidant Activity in Botanicals and Other Dietary Supplements. Pharmacopeial Forum 33: 810-814.

Prior, R., Wu, X., and Schaich, K. (2005). Standardized methods for the determination of antioxidant capacity and phenolics in foods and dietary supplements. J. Agric. Food Chem 53: 4290-302.

Prior, R.L., and Cao, G. (2000). Analysis of botanicals and dietary supplements for antioxidant capacity: a review. J AOAC Int. 83: 950-955.

Wu, X., Gu, L., Holden, J., Haytowitz, D.B., Gebhardt, S.E., Beecher, G., and
Prior, R.L. (2004b). Development of a database for total antioxidant capacity in foods: a preliminary study. J. Food Compos. Anal. 17: 407-422.

Quist, S.Y., Abo-khatwa, A.N., and Bin Lahwa, M.A. (2010). Screening of antioxidant activity and phenolic content of selected food items cited in the Holy Quran. Eur. J Bio Sci 2: 40-51.

Raso, G.M., Meli, R., Di Carlo, G., Pacilio, M., and Di Carlo, R. (2001). Inhibition of inducible nitric oxide synthase and cyclooxygenase-2 expression by flavonoids in macrophage J774A1. Life Sci. 68: 921-931.

Salah, A. (2005). Effect of date palm (Phoenix dactylifera) seed fibers on plasma lipids in rats. J King Saud Univ. 1: 117-123Al-Maiman.

Shaheen, M.A. (1990). Propagation of date palm through tissue culture: A review and an interpretation. AOAS, Ain Shams Univ., Cairo, Egypt. 35: 895-909.

Shahidi, F. (2000). Antioxidants in food and food antioxidants. NahrungFood 44: 158-163.

Shahidi, F. (2001). Extraction and measurement of total lipids. Current protocols in food analytical chemistry. In: Wrolstad, R.E. (Ed.). John Wiley and Sons, Inc, New York, NY, pp. 425-436.

Shahidi, F., and Alexander, D.M. (1998). Green tea catechins as inhibitors of oxidation of meat lipids. J. Food Lipids 5: 125-133.

Shahidi, F., and Zhong, Y. (2009). Antioxidants, polyphenols, and adipose inflammation. Adipose tissue and inflammation. In: Awad, A.B., and Bradford, P.G. (Ed.). CRC Press, Taylor and Francis Inc., Boca Raton, FL, pp. 233-234.

Singleton, V.L., and Rossi, J.A. (1965). Colorimetry of total phenolics with phosphomolybdic phosphotungstic acid reagents. Amer. J. Enol. Viticul. 16: 144-158.

Trasino, S.E., Kim, Y.S., and Wang, T.T.Y. (2009). Ligand, receptor, and cell type-dependent regulation of ABCA1 and ABCG1 mRNA in prostate cancer epithelial cells. Molec. Cancer Therap. 8: 1934-1945.

Van den Berg, R., Haenen, G.R.M.M., Van den Berg, H., and Bast, A. (1999). Applicability of an improved Trolox equivalent antioxidant capacity (TEAC) assay for evaluation of antioxidant capacity measurement of mixtures. Food Chem. 66: 511-517.

Vayalil, P.K. (2002). Antioxidant and antimutagenic properties of aqueous extract of date fruit (Phoenix dactylifera L. Arecaceae). J. Agric. Food Chem. 50: 610-617.

Vyawahare, N., Pujari, R., Khsirsagar, A., Ingawale, D., and Patil, M. (2009). Kagathara: Phoenix dactylifera: An update of its indegenous uses, phytochemistry and pharmacology. The Internet J. Pharmacol. 7(1): 1.

Wu, X., Beecher, G.R., Holden, J.M., Haytowitz, D.B., Gebhardt, S.E., and Prior, R.L. (2004a). Lipophilic and hydrophilic antioxidant capacities of common foods in the United States. J. Agric. Food Chem. 52: 4026-4037.

Wu, X., Gu, L., Holden, J., Haytowitz, D.B., Gebhardt, S.E., Beecher, G., and Prior, R.L. (2004b). Development of a database for total antioxidant capacity in foods: a preliminary study. J. Food Compo. Anal. 17: 407-422.

Ziouti, A., El-Modafar, C., Fleuriet, A., El-Boustani, S., and Macheix, J.J. (1996). Phenolic compounds in date palm cultivars sensitive and resistant to Fusarium oxysporum. Biologia Plantarum 38: 451-457.

Zhong, Y., Chiou, Y., Pan, M., and Shahidi, F. (2012). Anti-inflamatory activity of lipophilic epigallocatechin gallate (EGCG) derivatives in LPSstimulated murine macrophages. Food Chem. 134: 742-748. 